\title{
ARTÍCULOS
}

\section{MANTENER LA IDENTIDAD LUCHANDO Y ESCRIBIENDO. PRENSA MANUSCRITA EN LA CÁRCEL DE VENTAS (1946-1947)}

\author{
Mario Bueno Aguado \\ U.N.E.D; Universidad de Alcalá \\ Fundación Indalecio Prieto \\ mario.bueno@uah.es
}

\section{Keeping identity by fighting and writing. Handmade press in Ventas prison (1946-1947)}

Cómo citar este artículo/Citation:

Mario BUENO AGUADO (2017), "Mantener la identidad luchando y escribiendo. Prensa manuscrita en la cárcel de Ventas (1946-1947)", Hispania Nova, 15, págs. 147 a 171,

DOI: https://doi.org/10.20318/hn.2017.3484
Copyright: (c) HISPANIA NOVA es una revista debidamente registrada, con ISSN 1138-7319 y Depósito Legal M 9472-1998. Los textos publicados en esta revista están -si no se indica lo contrario- bajo una licencia Reconocimiento-Sin obras derivadas 3.0 España de Creative Commons. Puede copiarlos, distribuirlos y comunicarlos públicamente siempre que cite su autor y la revista y la institución que los publica y no haga con ellos obras derivadas. La licencia completa se puede consultar en: http://creativecommons.org/licenses/by-nd/3.0/es/deed.es
Resumen: Tradicionalmente, las mujeres que militan en organizaciones políticas de la izquierda se han visto relegadas a desempeñar tareas secundarias en las que se infravaloraban sus capacidades políticas. A pesar de esta situación y de la doble represión que aplicó el franquismo por su orientación política y su condición de mujeres, las presas políticas del franquismo desempeñaron un papel activo y adquirieron un protagonismo político inédito hasta en ese momento. El objetivo fundamental de su lucha era el de mantener su identidad y su dignidad como presas políticas. En esta tarea la escritura jugó un papel importantísimo.

En este artículo estudiaremos los periódicos manuscritos que escribieron las presas comunistas en la cárcel de Ventas durante los años 1946 y 1947. A partir del análisis de estas publicaciones trataremos de mostrar cómo se organizaban las presas comunistas en Ventas; cuales eran sus estrategias de resistencia; qué importancia tuvo para ellas la escritura y cómo afrontaron su rol de género orientado a la pasividad en un espacio político en el que tuvo un activismo constante.

Palabras clave: Franquismo, represión, mujer, resistencia, escritura..

Abstract: Traditionally, women who were members of left wing political organizations have been pushed into the background, and they have been compelled to do secondary tasks in which their political capacities have been undervalued. Despite of this situation and the double repression that francoism had put on them for both their women condition and their political orientation, political prisoners of francoism had an active role and they had a political prominence unprecedented until that moment. The main goal of their struggle was to keep their identity and their dignity as political prisoners. In that task, writing had a 
meaningful role.

In this paper, our aim is to study handwritten newspapers written by communist women prisoners in Ventas prison between 1946 and 1947. Through the analysis of these publications, we will be able to show how was the organization of communist prisoners in Ventas, which were their resistance strategies, which was the function that writing had for them and how they faced their gender role, aimed at a passive position, in a political space which had a constant activism.

Key words: Francoism, repression, women, resistance, writing. 


\section{MANTENER LA IDENTIDAD LUCHANDO Y ESCRIBIENDO. PRENSA MANUSCRITA EN LA CÁRCEL DE VENTAS (1946-1947)}

\section{Metodología y OBjetivos}

Enfrentadas a una doble represión motivada por su orientación política y su condición de mujeres, las presas políticas lucharon con todo lo que tenían a su alcance para defender su identidad y su dignidad. El papel de los periódicos manuscritos, y de la escritura en general, fue un elemento clave en su lucha. Por lo tanto, el presente artículo tiene como objetivo analizar esa doble represión y las estrategias de resistencias a través del papel que jugaron los periódicos manuscritos. Para enmarcarlo en un ámbito determinado se ha seleccionado los periódicos que elaboraron las presas comunistas en la prisión de Ventas durante los años 1946 y 1947.

Antes de empezar, hay dos aspectos muy necesarios que es preciso señalar en esta aproximación: por un lado, la historia que mayoritariamente se ha producido y difundido se enmarca en una perspectiva patriarcal y androcéntrica, inmersa en una especie de inconsciente histórico, o inconsciente androcéntrico, de acuerdo con Pierre Bourdieu, ${ }^{1}$ que provoca que muchas veces en estudios con pretensión de rigurosidad se olvide u omita el peso que tienen las mujeres como sujetos históricos. Por otro lado, la historiografía tradicional de la izquierda política y del movimiento obrero era ortodoxa en técnicas y metodología, y planteaba un análisis histórico exclusivamente vertical, centrada en el papel de los dirigentes y sin tener en cuenta a la militancia de base. ${ }^{2}$

Por lo tanto, teniendo en cuenta estos dos elementos, una de las herramientas más útiles para acercarnos a la vida de las presas del franquismo son los principios metodológicos de los que se dota la Historia de la Cultura Escrita. Mediante ellos, se trata de restituir la memoria y resaltar el papel histórico de personajes anónimos; por eso, teniendo en cuenta las condiciones sociales y materiales que hicieron posible cada texto, la Historia de la Cultura Escrita es una herramienta indispensable para una historia que está alerta frente a la labor de zapa de determinados historiadores que pretenden eludir los efectos de la lucha de clases, del género o de las múltiples desigualdades a lo largo de los siglos. ${ }^{3}$ De esta forma, tenemos una posibilidad idónea para acercarnos a las presas políticas del franquismo, las cuales, como

\footnotetext{
${ }^{1}$ Pierre BouRdieU, La dominación masculina, Barcelona, Anagrama, 2000, p. 73.

2 Eric HobsBaWm, El mundo del trabajo. Estudios históricos sobre la formación y evolución de la clase obrera, Barcelona, Crítica, 1987, p. 16.

${ }^{3}$ Antonio CASTILlo GómEZ, «El tiempo de la escritura. A modo de introducción», en Antonio CASTILLo Gómez (Coord.), Historia de la Cultura Escrita. Del Próximo Oriente antiguo a la sociedad informatizada, Gijón Trea, 2002, pp. 2021.
}

HISPANIA NOVA., 15 (2017), págs. 147-171 DOI: https://doi.org/10.20318/hn.2017.3484 
mujeres y como militantes de base, estaban doblemente invisibilizadas para los estudios historiográficos tradicionales.

Los nueve periódicos seleccionados para la realización de este artículo se fechan entre los años 1946 y 1947, y fueron producidos en la cárcel de Ventas por las presas de las JSU (Juventud Reclusa), ${ }^{4}$ y del PCE (Nuestro Guía ${ }^{5}$ y Mundo Obrero), ${ }^{6}$ si bien de una de las publicaciones objeto de estudio no se reconoce la autoría por parte de ningún organismo, partido o colectivo (Victoria), ${ }^{7}$ pero, como veremos, por la línea política que sigue está claramente producido por el entorno de estas organizaciones.

A partir del estudio de estos ejemplares se puede reflexionar sobre la forma de organización de las presas, vislumbrar de primera mano las estrategias qué usaron contra la doble represión, ver el papel que juega la escritura, la relación con otras organizaciones, etc. Otros aspectos sobre los que podemos estudiar a través de su estudio son los que se derivan de la reproducción de los roles de género: analizar cómo afrontaron su rol de género orientado a la pasividad en la esfera pública y al trabajo político de retaguardia en un espacio en el que tuvo lugar un activismo constante; qué diferencias había en la distribución de tareas con otros militantes comunistas. En definitiva, analizar estos periódicos permitirá convertir en protagonistas a las presas, al tiempo que concebirlas como sujetos activos frente a la represión de la que fueron objeto por parte del régimen franquista y frente a la anulación a la que han sido sometidas por la desmemoria histórica y por el androcentrismo imperante en los estudios históricos.

\section{BREVE CONTEXTUALIZACIÓN: REPRESIÓN FRANQUISTA EN VENTAS Y LA RESPUESTA DE LAS PRESAS}

A partir del 1 de abril de 1939 la guerra contra la República se prolongará por otros medios, ya no en los frentes de batalla, sino en los tribunales militares, en las cárceles, en los campos de concentración, en los batallones de trabajo e incluso en el exilio. Por eso, el Estado de Guerra continuó activo hasta $1948 .^{8}$ Desde 1939 se aplicó la represión sistemática que se había ensayado previamente durante la contienda, pero fue a partir de 1948 cuando el sistema represivo ya estuvo plenamente desarrollado, no volviendo a sufrir modificaciones sustantivas hasta el final del régimen franquista. ${ }^{9}$

Este es el contexto en el que nos movemos al analizar los periódicos manuscritos en la cárcel de Ventas: el momento en el que el aparato represivo del franquismo se estaba perfeccionando. La

\footnotetext{
${ }^{4}$ Archivo Histórico del Partido Comunista de España (AHPCE), Fondo Publicaciones Periódicas (FPP), carpeta 12, vol. 11, Juventud Reclusa, n. 11. Cárcel de Mujeres de Ventas, 1 de junio de 1946.

${ }^{5}$ AHPCE, FPP, 13/20, Nuestro Guía. Órgano Local del PC de Ventas, n. ${ }^{\text {s }} 1,2,4$ y 5. Cárcel de Mujeres de Ventas, enero-mayo de 1946.

${ }^{6}$ AHPCE, FPP, 12/33, Mundo Obrero. Órgano local del Comité Central del PCE. Sección Ventas, n. ${ }^{\text {os }} 11,12$ y extraordinario 1. de Mayo. Cárcel de Mujeres de Ventas, marzo-mayo de 1947.

${ }^{7}$ AHPCE, FPP, 13/3, Victoria, n. 1. Cárcel de Mujeres de Ventas, enero de 1946.

${ }^{8}$ Paul PRESTON, El holocausto español. Odio y exterminio en la Guerra Civil y después, Barcelona, Debate, 2011, p. 615.

${ }^{9}$ Gutmaro Gómez BRAVo, "Venganza tras la victoria: la política represiva del franquismo (1939-1948)», en Ángel VIÑAS (Ed.), En el combate por la historia. La República, la Guerra Civil y el Franquismo, Barcelona, Pasado\&Presente, 2012, p. 576.
} 
represión franquista estuvo acompañada de una persecución total. El mero hecho de que los ciudadanos de "confianza» del nuevo régimen declararan que un sospechoso era un indeseable o profesaba convicciones izquierdistas bastaba para proceder a su arresto y, a veces, hasta para llevarlo a un juicio. Las denuncias partían, por lo general, de quien había perdido a algún familiar en la violencia descontrolada que se había producido tras el inicio de la Guerra Civil. ${ }^{10}$ Se daba así la posibilidad a quienes habían sufrido de vengarse y castigar a los culpables y, de ese modo, resarcirse del dolor de forma pública. ${ }^{11}$

Para el franquismo, criminales y víctimas no podían vivir juntos: había que segregar a los militantes políticos para que no pudieran intoxicar a la sociedad, tal y como defendía en sus teorías el psiquiatra Antonio Vallejo Nájera, quien estaba convencido de la naturaleza psicosocial degenerativa e inferior del adversario. Precisamente, el análisis presuntamente científico de Vallejo Nájera es el que certifica y justifica la represión diferencial a la mujer, pues el hecho de que las mujeres engrosaran las filas del marxismo únicamente se debía a su resentimiento y a su fracaso social. Al desaparecer el freno matrimonial la mujer liberaba su «instinto de maldad», ya que era por naturaleza "propensa al crimen». ${ }^{12}$ Esta represión diferenciada tenía como objetivo revertir el proceso que se había iniciado en España durante la década de los años 30 en el que progresivamente se iba subvirtiendo el tradicional reparto de esferas pública y privada; la primera, asignada al varón, que participaba en el sistema de producción y en la vida política, y la segunda, propia de la mujer, relegada al ámbito doméstico, es decir, destinada al cuidado de los hijos y del hogar. Un papel de «verdadera mujer» de la época: madre abnegada y esposa sumisa y obediente. ${ }^{13}$

Demonizada por el franquismo como "la Roja», un "ser monstruoso», "sin sentimientos», entregada a "oscuras perversiones», la mujer carecía de reconocimiento de presa política, formando parte no de ese colectivo, sino del de las personas responsables de "delitos no comunes». ${ }^{14}$ La represión a las mujeres fue cualitativamente superior a la de los hombres, pues el franquismo aplicó castigos específicos para ellas, como el rapado de pelo, la ingestión de aceite de ricino, la violación, el escarnio público, el chantaje emocional con sus hijos, etc. ${ }^{15}$ Se trataba de poner énfasis en la moralidad y en la conducta privada haciéndoles pagar por ser la encarnación de un modelo de mujer diferente y completamente contrario al defendido por el régimen. Además, en las cárceles de mujeres, por su

\footnotetext{
${ }^{10}$ Paul PRESTON, El holocausto español..., op. cit., pp. 620-621.

${ }^{11}$ Gutmaro GómEz BRAVo, «Venganza tras la victoria...», op. cit., p. 576.

${ }^{12}$ Ricard VINYES, Irredentas. Las presas políticas y sus hijas en las cárceles franquistas, Madrid, Temas de hoy, 2002, pp. 51-68.

${ }^{13}$ Aurora MORCILlo GómEZ, «Feminismo y lucha política durante la II República y la guerra civil» en Pilar FolgUeRA (Coord.), El feminismo en España: dos siglos de historia, Madrid, Editorial Pablo Iglesias, 2007, p. 100.

${ }^{14}$ Fernando HeRnÁndez Holgado, Mujeres encarceladas. La prisión de Ventas: de la República al franquismo, 19311941, Madrid, Marcial-Pons, 2003, p. 50.

15 Ángeles EGIDO LEÓN, "Mujeres y rojas: la condición femenina como fundamento del sistema represor», Studia histórica. Historia Contemporánea, n. 29, 2011, pp. 29-30.
} 
hacinamiento desmesurado y la insalubridad, se alcanzaron niveles de mortalidad mucho mayores que en las cárceles masculinas. ${ }^{16}$

El caso de Ventas se trata de uno de los más representativos tanto de la represión franquista como de la resistencia de las presas, por lo que es un espacio idóneo para analizar el papel de estos periódicos. Culmen del ambicioso proyecto de Victoria Kent de construir un sistema penitenciario más moderno, seguro y humano, con separación de espacios entre presas políticas, madres y jóvenes, con sustitución de celdas comunes por celdas individualizadas, así como con la dotación de un cuerpo de funcionarios instruidos especialmente para atender en criterios de custodia y de educación a las reclusas; tras la entrada de las tropas de Franco en Madrid, acabó convirtiéndose en el símbolo por excelencia de la represión contra las mujeres del bando vencido, a quienes había que dar un "castigo ejemplarizante». ${ }^{17}$ De las 500 plazas individualizadas que tenía Ventas, que en 1935 eran ocupadas por tan solo 224 presas, se llegaría a albergar, según testimonios orales, entre 5600 y 11000 presas. Esta cifra se reducía a 1734 reclusas según las fuentes oficiales. ${ }^{18}$

Al margen de este baile de cifras, lo que está claro es que la sobrepoblación tuvo como consecuencia un hacinamiento desmesurado en la prisión de Ventas, lo que generaba muertes y enfermedades por las lamentables condiciones de vida: apenas había dos médicos para miles de presas y ningún ginecólogo, algo que empezó a mejorar a partir de 1944 y 1945. A esto hay que sumar la falta de higiene y la mala comida. A falta de conservarse un Libro Registro-Índice de defunciones, las investigaciones han cifrado los datos entre 1939 y 1945 en un total de 166 muertes: 81 fallecimientos por enfermedades, 1 suicidio ${ }^{19}$ y 84 presas ejecutadas. ${ }^{20}$

Sin embargo, si el objetivo de la represión franquista era el de doblegar y transformar, las presas de Ventas lo impidieron creando toda una tradición de lucha antirrepresiva que repercutió en la memoria colectiva y fueron objetos de fines ejemplarizantes. Gracias a estas acciones las presas resistieron mejor el día a día en prisión, pues tenían una motivación y un ejemplo a seguir. Así, en el imaginario colectivo de las presas de Ventas encontramos sucesos como la saca de «las menores», más comúnmente conocidas ahora como «las trece rosas», que se convirtieron en una leyenda en la prisión

\footnotetext{
${ }^{16}$ Gutmaro Gómez BRAvo, «Venganza tras la victoria: la política represiva del franquismo (1939-1948)», en Ángel Viñas (ed.), En el combate por la historia. La República, la Guerra Civil y el Franquismo, Barcelona, Pasado\&Presente, 2012, p. 585.

${ }^{17}$ Fernando HeRnández Holgado, Mujeres encarceladas..., op. cit., pp. 39-120.

${ }^{18}$ La cifra de 1734 la aporta el padrón municipal de la Villa de Madrid (diciembre, 1940). Es una cifra elevada, pero algo más baja que la que aportan algunos testimonios orales. Por ejemplo, Josefina Amalia Villa recordaba que una presa que había ingresado en prisión había informado de que el número de presas registrado en la pizarra de la entrada era de 5600 (abril-mayo, 1940). La cifra de 11000 la aporta es testimonio oral de Paz Azzati cuando narra a Tomasa Cuevas la despedida de Matilde Landa de la prisión de Ventas (agosto, 1942). Otro informe realizado por un preso y que se conserva en el AHPCE cifra a la población penitenciaria de Las Ventas en 8000 presas. Fuente: Fernando HeRnÁNDEZ Holgado, la prisión militante. Las cárceles de mujeres franquistas de Barcelona y Madrid (1939-1945) [Tesis Doctoral], Universidad Complutense de Madrid, Madrid, 2011, pp. $341-342$.

${ }^{19}$ Fernando HERnÁNDEZ Holgado, Mujeres encarceladas..., op. cit., pp. 148-226.

${ }^{20}$ Fernando HeRnÁNDEZ Holgado, La prisión militante. Las cárceles de mujeres..., op. cit., pp. 297-298 y 847-852. Esta cifra sustituye a la aportada con anterioridad de 78, en referencia al número de expedientes penitenciarios que se conservan. La nueva cifra ha sido aportada gracias al trabajo de asociación Familiares y Amigos de las víctimas de la represión franquista en Madrid.
}

HISPANIA NOVA., 15 (2017), págs. 147-171 DOI: https://doi.org/10.20318/hn.2017.3484 
por el impacto que supuso su ejecución, ya que demostró que contra la pena de muerte no valía ni la minoría de edad.

Otro mito colectivo de resistencia en la cárcel, que se transmitía oralmente a las nuevas reclusas, fue el de la labor llevada a cabo por Matilde Landa y la Oficina de Penadas, donde se atendía y asesoraba a las condenadas a muerte y que, aunque apenas consiguió ninguna victoria práctica, supuso un apoyo psicológico importantísimo. ${ }^{21}$ En el periodo de máxima congestión, entre 1939 y 1940, fue también clave la lucha por la creación de una enfermería de niños, coordinando a los distintos partidos y colectivos para lograr dicho fin. Toda lucha política partía así de una base personal y sentimental a la que las presas dotaban de contenido político. ${ }^{22}$

Este episodio supuso la primera organización colectiva de las presas de Ventas y ayudó a tejer la red clandestina de resistencia y solidaridad. Se organizaban en comunas o familias que aseguraban colectivamente la manutención y supervivencia de todas las reclusas. Estos mecanismos de supervivencia desbordaban las estructuras orgánicas de los partidos en prisión (también las que iban encaminadas al control de los resortes vitales de la prisión). Este proceso se produjo de forma pareja al de la reorganización de las distintas estructuras políticas. Ventas, al ser una prisión de galerías, favoreció una mayor capacidad de movimiento político, sobre todo cuando se cerraba la cárcel, ${ }^{23}$ y la propia prisión se convertía en una ciudad clandestina donde las presas tenían sus reuniones, organizaban sus actividades, creaban sus bibliotecas circulantes, etc. ${ }^{24} \mathrm{~A}$ partir de esa estructura se organizaron tanto el PCE como las JSU: dentro de cada galería hubo una dirección formada por varias compañeras, y para toda la cárcel una dirección central. Este era un modelo ya perfeccionado en 1946 y 1947 , si bien en los primeros años era más improvisado. ${ }^{25}$

Por sus características históricas (ser la cárcel de Victoria Kent), por la trayectoria de lucha militante de sus presas, por su emplazamiento en el "Madrid Heroico» que merecía un escarmiento ejemplar y por la propia estructura de la cárcel, que favorecía, como acabamos de ver, el activismo nocturno, Ventas fue una prisión activa que se llegó a convertir en un referente en la lucha por la resistencia y el mantenimiento de la identidad de las presas y los presos políticos del franquismo. De hecho, cuando se producían traslados, las presas de otras cárceles se beneficiaban de la formación política que habían adquirido las que procedían de Ventas, así como de los novedosos métodos de su cultura penitenciaria, normas de conducta y habilidad organizativa; ${ }^{26}$ destacaba su Comité de Unidad,

\footnotetext{
${ }^{21}$ Fernando HeRnÁNDEZ Holgado, Mujeres encarceladas..., op. cit., pp. 230-280.

${ }^{22}$ Fernando HeRnÁNDEZ Holgado, "La prisión militante Ventas (Madrid) y Les Corts (Barcelona)», Studia histórica. Historia Contemporánea, n.ㅇ 29, 2011,pp. 228-229.

${ }^{23}$ Ricard VINYES, Irredentas..., op. cit., p. 161.

${ }^{24}$ Verónica SIERRA BLAS, "La información como resistencia Periódicos manuscritos en las cárceles de Franco», en Jean Michel Desvois (ed.), Prensa, impresos, lectura en el mundo hispánico contemporáneo. Homenaje a JeanFrançois Botrel, Rennes, Université de Rennes 2-Haute Bretagne, 2005, p. 442.

${ }^{25}$ Fernando HeRnÁNDEZ Holgado, Mujeres encarceladas..., op. cit., p. 284.

${ }^{26}$ Santiago VEGA SOMBRía y Juan Carlos GARCíA FunES, «Lucha tras la rejas franquistas. La prisión central de mujeres de Segovia», Studia histórica. Historia Contemporánea, 29 (2011), p. 295.
} 
compuesto por representantes de todos los partidos, que logró generar una cohesión entre comunistas, anarquistas y socialistas, ${ }^{27}$ y su biblioteca circulante y colectiva. ${ }^{28}$

\section{ESCRITURA Y CÁRCEL: LA PRODUCCIÓN Y DIFUSIÓN DE LOS PERIÓDICOS MANUSCRITOS}

La escritura en las cárceles de Franco se convirtió en un arma ideológica e identitaria, al tiempo que en un mecanismo de resistencia frente al control y al sometimiento. Son múltiples las referencias e interpretaciones que se han hecho de los análisis de Michel Foucault sobre la función de las cárceles y el papel de la escritura en reclusión. ${ }^{29}$ Foucault sostiene que el objetivo de todo régimen y entidad opresora es la anulación de la identidad del preso, la destrucción de sus lazos con el mundo exterior (personales y políticos) y la voluntad de crear una nueva persona, y para todo ello el uso de la escritura y de la lectura resultó clave.

La escritura es empleada por las autoridades penitenciarias como método de adiestramiento y sometimiento. En prisión, se exigió la constante participación del preso en la elaboración de múltiples productos escritos, ${ }^{30}$ algunos de carácter administrativo, otros más personales, sin faltar aquellos con una cierta dimensión pública, informativa y propagandística. Entre estos últimos estarían los periódicos y boletines, donde destaca Redención, el único periódico permitido en las cárceles de Franco. $\mathrm{Ni}$ siquiera la prensa de la calle, a pesar de que esta también debía ser solo afín al régimen, podía ser leída por los reclusos. Redención era un periódico escrito por presos y para presos, donde estos leían las humillantes palabras de sus compañeras y compañeros, quienes reconocían públicamente, con el fin de reducir su condena, sus pecados e ignorancia, y se arrepentían de haber traicionado al espíritu de la patria, pidiendo perdón; por ello, se trataba de una importante herramienta del régimen para conseguir la anulación de las reclusas y reclusos. El periódico tenía una tirada de unos 60000 ejemplares, y los presos podían suscribirse de forma «libre», dado que estar suscrito solía ser condición para poder recibir visitas, ${ }^{31}$ por eso el número de suscriptores fue muy elevado. También había otras actividades que conllevaban redimir penas, tales como escribir el diario de la galería, confeccionar el archivo de Redención o copiar párrafos del catecismo o de otras obras religiosas o culturales elegidas por el maestro o el capellán. ${ }^{32}$

\footnotetext{
${ }^{27}$ Montserrat DuCH PLANA, «Una perspectiva de género de la represión concentracionaria franquista a partir del caso de la cárcel de las oblatas de Tarragona (1939-1943)», Studia histórica. Historia Contemporánea, 29 (2011), p. 331.

${ }^{28}$ Santiago VeGA SOMBríA y Juan Carlos GARCíA FUnES, "Lucha tras la rejas franquistas...», op. cit., p. 297.

29 Un ejemplo de ello serían las referencias en las aportaciones Verónica SIERRA BLAS, «La información como resistencia...», op. cit., p. 439; Antonio CASTILLO GÓMEZ, "Escribir para no morir. La escritura en las cárceles franquistas», en Feliciano MonTERo García y Antonio CASTILLo Gómez (Coords.), Franquismo y memoria popular, Madrid, Siete Mares, 2003, p. 20; y Ricard VINYES, «Doblegar y transformar...», op. cit., p. 37.

${ }^{30}$ Verónica SIERRA BLAS, «El panóptico epistolar. Censura carcelaria y estrategias comunicativas en las prisiones de la guerra y posguerra española», en Antonio CASTILLO GóMEZ y Verónica SIERRA BLAS (Dirs.), Cartas-Lettres-Lettere. Discursos, prácticas y representaciones epistolares (siglos XIV-XX), Alcalá de Henares (Madrid), Universidad de Alcalá, 2014, p. 394.

${ }^{31}$ Eduardo RUIz BAUTISTA, «Prisioneros del libro: leer y pensar en las cárceles de Franco», en Feliciano MONTERO García y Antonio CASTILLo Gómez (Coords.), Franquismo y memoria popular..., op. cit., pp. 118-119.

32 Domingo Rodríguez TeIJeIRo, Las cárceles de Franco, Madrid, La Catarata, 2011, p. 161.
} 
Como planteaba uno de los pioneros de los estudios sobre cultura escrita desde una perspectiva social, el lingüista soviético V. A. Istrin, las necesidades sociales ocupan un lugar muy especial dentro del desarrollo de la escritura. ${ }^{33}$ Frente a esta estrategia violenta y coactiva de arrebatamiento de la identidad, el preso tenía dos opciones: o plegarse y asumir su redención o, por el contario, ejercer resistencia. ${ }^{34}$ Es en este contexto en el que, frente a las prácticas de escritura carcelaria "oficiales», se desarrollaron las escrituras clandestinas, cuya función principal era mantener la identidad del preso. Dentro de ellas se encuadrarían los periódicos manuscritos, objeto de este trabajo, así como los diarios, las memorias, las cartas, los graffitis o los partes. ${ }^{35}$ Por eso, no es de extrañar que en sus testimonios las presas rara vez hagan referencia a la escritura como evasión o entretenimiento. ${ }^{36}$ No era ese su fin: escribir era su trinchera y el lápiz o la pluma, su arma para combatir en prisión y seguir su lucha por una sociedad mejor.

La activa relación de los presos con la escritura refleja cómo las presas y los presos políticos no fueron exclusivamente meros sujetos de sufrimiento, sino personas capaces de ver lo que ocurría a su alrededor, analizarlo y rebatirlo con los medios que tuvieran a su disposición. ${ }^{37}$ Esta realidad no se corresponde con la foto fija tradicional de la vida interna en prisión. Por poner un ejemplo, Gregorio Morán, en su trabajo dedicado al PCE, plantea que las prisiones eran «inmensos depósitos de presos», donde las noticias llegaban "sesgadas» y apenas se interpretaban, "porque desde el momento en que [los militantes] entraban en prisión dejaban de ser líderes políticos y pasaban a la categoría de heroicos ciudadanos que se disponían a mostrar su dignidad muriendo como valientes». ${ }^{38} \mathrm{Si}$ bien reconoce que la historia del activismo político en las cárceles de Franco estaba «históricamente dispersa y mal contada", vemos que las fuentes escritas resultan fundamentales para descubrir la vida interna de los presos y revelan su activísimo papel político.

En el caso concreto de los periódicos manuscritos, estos eran el resultado de una intensa labor educativa, cultural y política, generalmente desarrollada por los presos más comprometidos. Se producen en un número importante de cárceles franquistas, ${ }^{39}$ aunque es cierto que la mayoría de estos periódicos se crean en las cárceles de hombres, los cuales cuentan con una escritura más hábil y un mayor cuidado en su edición (dibujos, gestión de márgenes, alineación más regular, etc.). Esto se debe sin duda a la brecha importante de analfabetismo en detrimento de las mujeres quienes, al haber estado relegadas a la esfera privada, no pudieron acceder a una educación formal o en igualdad de condiciones que los varones. En ese sentido, los periódicos de Ventas constituyen una excepción en el universo penitenciario de las presas de Franco, aunque también hay evidencias que nos muestran que no solo se elaboraron en Ventas sino que también se producen en otras prisiones de mujeres como la

\footnotetext{
${ }^{33}$ Armando PETRUCCI, Historia de la escritura e historia de la sociedad, Valencia, Universitàt de Valencia, 1998, p. 3.

${ }^{34}$ Eduardo RUIZ BAUTISTA, «Prisioneros del libro...», op. cit., p. 105.

${ }^{35}$ Antonio CASTILLO GÓMEZ, «Escribir para no morir...», op. cit., pp. 30-48.

${ }^{36}$ Eduardo RUIz BAUTISTA. «Prisioneros del libro...», op. cit., p. 105.

${ }^{37}$ Ricard VINYES, Irredentas..., op. cit., pp. 13-14.

${ }^{38}$ Gregorio Morán, Miseria y grandeza del Partido Comunista de España 1939-1985, Barcelona, Planeta, 1986, p. 39.

39 Para una sintética relación de publicaciones manuscritas producidas en las cárceles de Franco se puede consultar: Verónica SIERRA BLAS, «La información como resistencia...», op. cit., pp. 450-451
} 
de Segovia. ${ }^{40}$ Las páginas de estos periódicos se convirtieron en muchas ocasiones en espacios de formación, que junto a otras actividades como los cursos para combatir el analfabetismo, consiguieron poner en marcha planes de aculturación y propaganda que contrarrestaran a los desplegados por el régimen. ${ }^{41}$ La escritura se entendió como una herramienta para la formación y capacitación de cuadros políticos, y como mecanismo de reivindicación de la identidad política de los presos y presas, pues si morían las convicciones por las que habían sido encarcelados, ¿̇qué quedaba de ellos? ${ }^{42}$.

Entrando ya en el análisis de los periódicos manuscritos, estos se elaboraban y producían de forma encubierta al caer el sol, cuando la estructura de Ventas permitía que se desarrollara esa «ciudad clandestina». Buena parte de la información que estos contenían se elaboraba a partir de las noticias que las presas recibían a través de canales de información muy variados: periódicos de la calle que entraban en la prisión sorteando la censura, información cruzada en la correspondencia con presos y presas de otras cárceles, comunicaciones escritas y orales con familiares y amigos, consignas enviadas por el partido o producidas en las diferentes reuniones de los militantes del mismo en prisión, etc. ${ }^{43}$ La confección de los periódicos era fruto del esfuerzo colectivo, de ahí que en Nuestro Guía, cuyo primer número lo edita solamente la dirección unitaria de la cárcel de Ventas, se hiciera este llamamiento ${ }^{44}$ a la militancia para que participara en su elaboración:

Al editar el P[artido] este periódico lleva los fines siguientes: que el trabajo sea más amplio y todas y cada una de las militantes, tengan en las columnas de Nuestro Guía campo abierto para expresar sus iniciativas, sus dudas, sus opiniones. ${ }^{45}$

El Ilamamiento fue efectivo, ya que presas que militaban en las células repartidas por las galerías de la prisión mandaron sus colaboraciones a la dirección unitaria, y esta las felicitó y posteriormente publicó sus contribuciones:

A las Céllula]s no 3 y 5 de la 3ª [galería] derecha, y a las [células] 1, 2 y 5 de la 2ª [galería] derecha, que han mandado su colaboración espontánea a Nuestro Guía de hoy, esta dirección les manda una sincera felicitación. No desmayéis y seguid así, camaradas. ${ }^{46}$

La elaboración colectiva también fue el sistema empleado por las JSU, pues aparecen artículos firmados por distintas células de la prisión, aunque estas no tienen nombres numéricos, sino que sus denominaciones evocan a históricos dirigentes, como Trifón Gómez, el que fuera secretario general de la Unión de Juventudes Comunistas de España (UJCE), o a hechos significativos, como la célula "Las Menores», haciendo referencia a las trece rosas. ${ }^{47}$ Muchos de estos artículos, a pesar de ser firmados

\footnotetext{
${ }^{40}$ Santiago VegA SOMBRíA y Juan Carlos GARCÍA FUnES, «Lucha tras la rejas franquistas...», op. cit., p. 313;

${ }^{41}$ Antonio CASTILLO GóMEZ, «Escribir para no morir...», op. cit., p. 51.

${ }^{42}$ Ricard VINYES, Irredentas..., op. cit., p. 156.

${ }^{43}$ Verónica SIERRA BLAS, «La información como resistencia...», op. cit., p. 455.

${ }^{44}$ Todos los textos que se transcriben en este trabajo han sido actualizados ortográficamente siguiendo las normas lingüísticas convencionales.

${ }^{45}$ AHPCE, FPP, 13/20, Nuestro Guía, n.o 1, enero de 1946, p. 1.

${ }^{46}$ AHPCE, FPP, 13/20, Nuestro Guía, n.o 4, abril de 1946, p. 2.

${ }^{47}$ AHPCE, FPP, 12/11, Juventud Reclusa, n.o 11, 1 de junio de 1946, pp. 3-4.
} 
por la célula, son personales, es decir, hablan en primera persona de aspectos individuales de una militante en concreto. Al igual que la letra de los periódicos se hacía para que fuera impersonal y no se pudiera reconocer a la autora material, ${ }^{48}$ la firma colectiva respondía a esa misma intención: proteger la identidad de quienes participaban en la elaboración de estos productos.

Frente a las alabanzas a la colaboración, también se producen críticas por la situación inversa, hacia militantes que se habían comprometido a redactar un texto y finalmente faltaron a su compromiso:

Recoge esta dirección con disgusto que en la 3a [galería] izquierda es acogida con frialdad y lentitud la colaboración que es pedida para Nuestro Guía. ¿Creéis camaradas que esto les está permitido a los comunistas? ¿Creéis que puede marchar bien nuestro P[artido] si todos sus militantes no le prestan su colaboración? Esta lentitud ha traído como consecuencia que el artículo que habéis mandado para este número por llegar tarde no pueda ser insertado. Para que esto no se repita procurad ser más dinámicas. ${ }^{49}$

Una vez que se disponía de toda la información, llegaba la fase de producción propiamente dicha del periódico. Las presas se organizaban en grupos de trabajo en función de su formación, capacitación técnica, inquietudes, etc. Se leía, se seleccionaba la información y luego se dictaba a la persona que se encargaba de copiarla. El último paso antes de poner el periódico en circulación era entregárselo a las militantes que lo ilustraban. Dado su carácter clandestino, fue necesaria la designación de vigilantes y guardianes durante la producción de los periódicos, con el fin de evitar que fueran descubiertas mientras trabajaban en las celdas. Con respecto a la lectura, esta variaba en función del momento que se viviera en prisión. Si no había ningún problema, el periódico se leía en voz alta en las celdas o en la reunión de la noche, donde la lectura de las noticias era el acto estrella. Cuando no se podía leer en voz alta, se leía en grupos más pequeños al salir al patio, o se transmitía de viva voz sin papeles, aprendiéndose las presas las noticias de memoria. ${ }^{50}$

Además, había una intencionalidad de perduración del documento, algo que era complicado y peligroso, dada su condición secreta. De hecho, los que se han conservado son aquellos que pudieron sacarse al exterior burlando la censura y depositarse en domicilios particulares o en las sedes de las distintas organizaciones, y muchos tuvieron que ser escondidos en lugares a los que nunca se pudo volver o ser destruidos por los lectores tras leerlos para evitar represalias. ${ }^{51}$

Así, en las páginas de Mundo Obrero se informaba de cómo el periódico había conseguido salir de prisión y llegar al Partido: «los últimos números de Mundo Obrero de Ventas ha llegado a manos de nuestro C[omité] C[entral].», ${ }^{52}$ al igual que en Victoria se añade una nota al final del ejemplar destinado al exterior que evidencia que el periódico salió de los muros de la cárcel: "os mandamos para que lo conozcáis el saludo que se ha hecho del 1 [er día] de año y que se ha leído a todo el mundo.». ${ }^{53}$ Es posible que este interés por parte de las presas en que se conozca su actividad por parte de los órganos

\footnotetext{
${ }^{48}$ Verónica SIERRA BLAS, «La información como resistencia...», op. cit., p. 456.

${ }^{49}$ AHPCE, FPP, 13/20, Nuestro Guía, n. 4, abril de 1946, p. 3.

${ }^{50}$ Verónica SIERRA BLAS, «La información como resistencia...», op. cit., pp. 456-459.

51 Ibídem, p. 450.

52 AHPCE, FPP, 12/33, Mundo Obrero, n.o 11, marzo de 1947, p. 2.

${ }^{53}$ AHPCE, FPP, 13/3, Victoria, enero de 1946, p. 12.
} 
superiores del PCE estuviera destinado también a visualizar que ellas también eran capaces de desarrollar una actividad política en la que se desenvolvieran tan bien como sus camaradas varones.

Con respecto a las características materiales, son bastantes semejantes entre sí las publicaciones que han redactado las presas del PCE, Mundo Obrero y Nuestro Guía. Comparten una estructura similar en cuanto a extensión, distribución del texto por columnas y secciones, las cuales, por norma general, se repiten en los siguientes números. Tienen espacios para la formación, para la información mundial, para el conocimiento de los dirigentes, para la comunicación de directrices, etc. Por su parte, Juventud Reclusa tiene una distribución distinta de contenidos sobre temas muy concretos de la prisión, aunque como no se han conservado más ejemplares no podemos saber si sigue una misma estructura o esta va cambiando número tras número. Por su parte, Victoria fue un número monográfico que tenía como función únicamente difundir un comunicado que habían preparado las presas para el primer día del año de 1946. En lo que sí que destaca Victoria es que la mitad de las páginas aparecen mecanografiadas y no manuscritas, por lo que se puede suponer que o esa parte fue confeccionada fuera o que las presas se aprovecharon de los resortes orgánicos de la prisión, algo menos probable por la peligrosidad que conllevaba este tipo de acciones.

A pesar de las dificultades que supuso la realización de estos periódicos manuscritos en un espacio tan represivo como la cárcel de Ventas, estos no perdieron algunas características que acompañaron a las publicaciones comunistas durante los años previos como, por ejemplo, una concepción totalmente moderna, recurriendo a elementos propios de la prensa popular del siglo $\mathrm{xx}$ (grandes titulares, proliferación de información gráfica, etc.), que buscaban una implicación emocional del lector para la transmisión de consignas políticas, frente a otros formatos más clásicos. ${ }^{54}$ Por esta razón, predominan los dibujos y representaciones gráficas. La portada de Victoria es en color y representa el cambio de situación política que querían las presas de Ventas en España para el año 1946: con base en la unidad de la izquierda (IMAGEN I). Juventud Reclusa se acompaña de representaciones gráficas que hacen referencia a las consignas de la organización, al igual que diversas ilustraciones que hacen referencia al contexto carcelario como, por ejemplo, barrotes, rejas, cadenas, etc. (IMAGEN II). Además, destaca la presencia de una canción acompañada de una partitura y esta sigue las normas de la escritura musical (la clave, la armadura, los signos...), lo que puede significar que las presas que elaboraban el periódico tenían conocimientos de música. Por su parte, Mundo Obrero y Nuestro Guía continúan con las representaciones corporativas en sus respectivas cabeceras. (IMAGEN III Y IV)

En los casos de Mundo Obrero y Nuestro Guía todas las publicaciones están escritas con varias tintas, generalmente roja y negra, y, en menor medida, azul, que usan de forma diferenciada para enfatizar consignas, resaltar títulos de artículos o citar frases de dirigentes célebres. Sin embargo, el nivel de conservación de dichas tintas no es igual, ya que algunas se han borrado por consecuencias ambientales. Como paradoja de la conservación del testimonio escrito, en el caso de Nuestro Guía se han perdido múltiples enfatizaciones, testimonios y citas célebres de Dolores Ibárruri, entre otros dirigentes, al haberse resaltado en rojo. Ahora solo quedan las palabras escritas y anónimas de las presas, militantes de base, alejadas de las discusiones, estrategias y debates del Comité Central, encuadradas en esa masa anónima y combativa que era «El Partido».

\footnotetext{
${ }^{54}$ Fernando HeRnÁNDEZ SÁNCHEZ, Guerra o revolución: el Partido Comunista de España en la Guerra Civil, Barcelona, Crítica, 2010, p. 299.
} 


\section{DE LA VIDA COTIDIANA A LA ACCIÓN POLÍTICA: LO QUE NOS TRANSMITE LA PRENSA MANUSCRITA EN LA CÁRCEL DE VENTAS}

Son varias las funciones esenciales de los periódicos manuscritos carcelarios: son elementos de reorganización política en las cárceles; son espacios fundamentales para la resistencia y, sobre todo, son medios de denuncia de las atrocidades del régimen. ${ }^{55}$ Dichas funciones se pueden apreciar claramente en el corpus documental analizado. Sin embargo, dada la especificidad de la militancia política de las presas, y su condición de mujeres, estos productos también sirvieron para definir los roles de género, permitiéndonos conocer cómo se autorrepresentaron las presas, su formación en función de los distintos perfiles, las relaciones con otras organizaciones políticas, etc. A continuación analizaremos los aspectos que se derivan del contenido de estas publicaciones.

\section{La acción política en prisión}

La acción estratégica y política que nos trasladan los periódicos manuscritos producidos en Ventas está fuertemente marcada por el contexto histórico de su producción. A medida que se fue desarrollando la II Guerra Mundial, la posibilidad de una intervención aliada aumentó el activismo político y la conflictividad en las cárceles ${ }^{56}$; al mismo tiempo, se volvía a organizar el Gobierno de la II República en el exilio bajo la presidencia de José Giral (agosto, 1945). En ese momento, el PCE -tras múltiples virajes estratégicos desde el final de la Guerra Civil ${ }^{57}$ apostaba por sumarse al clima de unidad que empezaba a plantearse en el exilio republicano, traduciéndose en la entrada de Santiago Carrillo como ministro sin cartera del Gobierno de la II República en el Exilio, representando al PCE. Además, tras la condena de la ONU, el régimen de Franco se encontraba en una posición de máxima debilidad. Por eso, como se afirmaba en Victoria, 1946 tenía que ser «el año de la victoria».

\footnotetext{
${ }^{55}$ Verónica SIERRA BLAS, «La información como resistencia...», op. cit., pp. 451-454.

${ }^{56}$ Gutmaro Gómez Bravo, El exilio interior. Cárcel y represión en la España franquista, 1939-1950, Madrid, Taurus, 2009, p. 132.

${ }^{57}$ Estos virajes estuvieron marcados por las directrices que trasladaba la Unión Soviética al PCE en función del desarrollo de la II Guerra Mundial. En un primer momento, el PCE consideró que el Frente Popular seguía vigente, a pesar de la desconfianza que había generado en ellos el golpe de Casado. No obstante, a partir del pacto germano-soviético (agosto, 1939) el PCE dio por finalizado al Frente Popular y volvió a sus tesis anteriores a 1935 (crítica a la constitución de 1931 por ser una norma de una República reformista y burguesa). Con el ataque nazi a la Unión Soviética en 1941, la postura del PCE cambió planteando una política de «Unión Nacional» que se traducía en la alianza de todas las fuerzas sociales y políticas que estuvieran dispuestas a combatir al régimen de Franco (exceptuando a los "casadistas») con el objetivo de restablecer la II República. Aunque esta política consiguió sacar del ostracismo al PCE y reactivar su alianza con los sectores «negrinistas» de las organizaciones del exilio, se volvió a resentir con otro giro del PCE en septiembre de 1942, cuando plantearon que la alternativa a Franco era una asamblea constituyente (sin citar a la II República). Sin embargo, tras la convocatoria de las Cortes de la II República en el Exilio (enero, 1945) y la posibilidad de que resurgieran las instituciones republicanas, forzó a múltiples sectores del exilio a revisar sus posturas, por lo que el PCE acordó retomar su política inicial de Unión Nacional. Visto en: Hartmut HEINE, La oposición política al franquismo, Barcelona, Crítica, 1983, pp. 85-161; Gregorio MoRÁN, Miseria y grandeza del Partido Comunista de España 1939-1985, Barcelona, Planeta, 1986, pp.96-114.
}

HISPANIA NOVA., 15 (2017), págs. 147-171 DOI: https://doi.org/10.20318/hn.2017.3484 
¡Mujeres de Ventas! España reclama la colaboración de todos sus hijos para rescatar la República y la Independencia. Seamos nosotras las primeras en proporcionársela, ofreciéndole en este año que hoy principia el arma más eficaz de que disponemos: iNuestra Unidad! ${ }^{58}$

En la misma línea abría su editorial Nuestro Guía: «que a través de todas y cada una de sus líneas [de Nuestro Guía], nos llegué con claridad evidente una consigna férrea: "la de luchar" y un anhelo único "el de unidad"». ${ }^{59}$ Unidad y lucha eran algo más que una consigna, eran una necesidad:

[...] nos dirigimos hoy a nuestros legítimos representantes para exigirles (porque nuestra condición de presas nos da derecho a exigir, ya que dimos lo más valioso de la vida, la libertad) acción y decirles: no dejéis pasar un día más sin señalar al pueblo su camino [...]. Pensad que cada hora que pasa pone nuevas víctimas en manos de los verdugos falangistas; que cada hora que pasa lleva aparejadas torturas sin nombre en los sótanos de Gobernación; que cada hora que pasa aumenta el hambre y la depauperación del pueblo; que cada hora que pasa son cientos los hombres y mujeres que mueren de agotamiento en las cárceles franquistas, y no dejéis un solo momento más sin que nuestra voz llegue al pueblo que alienta con la esperanza de un mañana próximo que devuelva su libertad [...]. Nosotras clamamos hoy pidiendo actividad y rapidez. Las horas de prisión van minando nuestra naturaleza y anulando poco a poco nuestro espíritu [...]. Queremos combatir porque no queremos seguir viendo nuestra Patria en manos de criminales y traidores. No nos importa la vida, porque lo que hacemos ahora no es vivir, y la entregaríamos gustosas si sirviera nuestra sangre para regar los campos de donde surgiera una España libre. ${ }^{60}$

Un grito agónico, sin duda, el que salía de la cárcel de Ventas. Por eso, desde las páginas de Nuestro Guía también se apelaba a la premura de lograr la unidad pretendida:

[N]o se puede esperar ni un solo momento. Cada día que pasa es una posibilidad mayor que se brinda al enemigo, y un retroceso para la consecución de nuestros fines. Debemos trabajar desde donde sea y con quien sea, con tal que el trabajo vaya encaminado a la instauración de la República. Han de dejarse de lado todos los problemas que supongan discusiones estériles y nos ha de guiar únicamente el propósito para aumentar el número de acciones de lucha y el número de fuerzas que tomen parte en estas. ${ }^{61}$

La referencia expresa a la República no es casual, muestra la visión de la militancia del PCE a las conversaciones que se empezaban a iniciar entre algunos sectores del PSOE con una parte de los monarcas antifranquistas con el fin de negociar una alternativa política común a la situación política de España. Las propuestas rondaban en torno a la organización de un plebiscito para definir la forma de Estado ante una -en ese entonces - posible caída del régimen de Franco. ${ }^{62}$ La idea del plebiscito implicaba, de facto, renunciar a la legitimidad de la II República, por eso las y los comunistas temían que estos contactos acabaran en una hipotética restauración monárquica, con apoyo internacional, en la

\footnotetext{
${ }^{58}$ AHPCE, FPP, 13/3, Victoria, enero de 1946, p. 3.

${ }^{59}$ AHPCE, FPP, 13/20, Nuestro Guía, n.o 1, enero de 1946, p. 1.

${ }^{60}$ AHPCE, FPP, 13/3, Victoria, enero de 1946, p. 5.

${ }^{61}$ AHPCE, FPP, 13/20, Nuestro Guía, n. 2, febrero de 1946, p. 1.

62 Sobre estas cuestiones se puede leer en: Octavio CABEZAS, Indalecio Prieto, socialista y español, Madrid, Algaba, 2005, pp. 531-586; Joan GARCÉs, Soberanos e intervenidos. Estrategias globales, americanos y españoles, Madrid, Siglo XXI, 1996, pp. 32-51; José Luis de la Granja SAINZ, Indalecio Prieto: Socialismo, democracia y autonomía, Madrid, Biblioteca Nueva, 2013; y en Luis C. HeRnANdo (Ed.), ¿República o Monarquía? Libertad. Correspondencia entre Araquistáin, Prieto y Largo Caballero entre 1945 y 1949, Madrid, Fondo de Cultura Económica, 2012.
} 
que una parte de la oposición a Franco - el PCE, esencialmente- jugara un nulo papel. Ese es el motivo por el que desde Nuestro Guía se critican las «nuevas corrientes de pasividad por parte de sectores que siempre están confiando en que la solución de nuestra situación ha de ser resuelta desde fuera», señalando el peligro de «una inminente Monarquía, esta corriente [la que defiende la vuelta a la monarquía] nos lleva a pasos agigantados a un retraso de casi veinte años». ${ }^{63}$

La lucha constante para no dar paz al régimen era la consigna a seguir. Por eso tuvo tanta importancia para las presas la huelga de hambre de 1946, que se sumaría a esa memoria colectiva de Ventas que se fue creando junto a los fusilamientos de "Las Menores», la oficina de penadas de Matilde Landa o la fuga de dos condenadas a muerte en noviembre de $1944 .{ }^{64}$ Los resultados de esa huelga son analizados en Nuestro Guía:

Impregnadas del más magnifico espiritu de lucha, sacrificio y compenetración con los momentos políticos actuales, habéis demostrado un gran temple de acero abriendo una gesta heroica en vuestra historia de presas, con esa [chuelga de hambre?] sostenida durante cuatro días. [...] Es un magnífico ejemplo que ni una sola comunista, ni simpatizante siquiera, haya saboteado este hecho extraordinario. Así debe ser, camaradas [...]. Ya veis que los resultados obtenidos son francamente satisfactorios. Que ellos nos alienten para emprender nuevas acciones que demuestren al enemigo nuestra fuerza, que nos proporcionen las mejoras de vida a que tenemos derecho y que sirvan para minar al régimen maldito de Franco y la Falange, al que, como patriotas y comunistas, tenemos el deber de derribar. iAdelante por este camino, comunistas de Ventas! Emprendamos con tacto y habilidad una extensa labor política con la base de los demás sectores a fin de crear una corriente de acción y unidad en toda la prisión que arrollará cualquier posición pasiva, que alguien intentara oponer en un momento determinado. ${ }^{65}$

Pero no en todas las acciones políticas hubo una respuesta tan unánime. La discusión hay que buscarla en aquellas acciones en las que se producía una fusión de realidades personales y políticas, como el boicot de las presas comunistas a las visitas de niños a la prisión en las fiestas de Reyes, Navidad y la Merced, desplegadas por el régimen para proyectar una imagen bondadosa y generosa del sistema penitenciario de cara al exterior. ${ }^{66}$ Así, Nuestro Guía destaca que:

[L]as mujeres de Ventas han sabido anteponer la lucha política a sus sentimientos más queridos. Madres, hermanas, abuelas, todas se han sacrificado con la sonrisa en los labios, sin una tibia protesta, sin una queja ante lo que suponía el venirse abajo la ilusión de estrechar contra sus pechos a los pequeñuelos. ${ }^{67}$

Sin embargo, el acto no debió de ser tan unánime cuando en la sección «Estímulo y crítica» se plantea la crítica a "las camaradas que saboteando la posición del P[artido] han consentido tener con ellas a sus pequeñuelos el día 6 . ¿Cómo podremos las comunistas [ilegible] si somos nosotras las primeras en no cumplirla?». ${ }^{68}$

\footnotetext{
${ }^{63}$ AHPCE, FPP, 13/20, Nuestro Guía, n.o 2, febrero de 1946, p. 1.

${ }^{64}$ Fernando HeRnÁNDEZ Holgado, «La prisión militante...», op. cit., p. 230.

${ }^{65}$ AHPCE, FPP, 13/20, Nuestro Guía, n.o 2, febrero de 1946, p. 2.

${ }^{66}$ Fernando HERNÁNDEZ HOLGADO, «La prisión militante...», op. cit., p. 231.

${ }^{67}$ AHPCE, FPP, 13/20, Nuestro Guía, n.o 1, enero de 1946, p. 3.

${ }^{68}$ Ibídem, pp. 4-5.
} 
Las relaciones entre el PCE y el PSOE no siempre fueron buenas. A pesar de que en determinados momentos se trabajara de forma conjunta dejando a un lado las diferencias que se habían producido a lo largo de la guerra, seguían existiendo desconfianzas mutuas. Un ejemplo claro de ello es lo que sucedió en un acto que organizaron las células de la segunda galería del PCE en relación con su política a seguir desde 1939. En dicho acto, tal y como cuenta Nuestro Guía, las militantes del PSOE intervinieron «para atacar al PC, lanzando acusaciones categóricas contra él. Éste que se creyó en el deber de hacer su defensa, esclareciendo con ejemplos y razonamientos contundentes su conducta intachable, reanudó el acto dos días después». La controversia fue que una socialista se hizo dueña del debate, llevando la dirección del mismo. ${ }^{69}$ El que en páginas siguientes hicieran un suplemento especial sobre «los pactos», repasando desde el pacto de El Pardo, hasta el pacto del Frente Popular, pasando por los republicanos-socialistas, etc., parece indicar que el motivo del debate fue el pacto germanosoviético, justificado por las presas comunistas -siguiendo el relato oficial de la dirección del PCE- para que la URSS tuviera «una tregua de dos años próximamente para prepararse a resistir el asalto del mundo capitalista, que bien claro lo vemos ahora le era completamente hostil. [...]. Dos años a cuyo final han estado en condiciones de ser el único pecho robusto que se opusiera al torrente fascista que lo negaba todo». ${ }^{70}$

Al margen de este encontronazo momentáneo, y otros muchos que había en el día a día entre presas socialistas y comunistas, la intención del PCE en Ventas seguía siendo la de la «exigir que se acabe con la doble división socialista». ${ }^{71}$ De hecho, se criticó la poca unidad de las presas, no solamente en lo político, sino en lo personal: «El P[artido] señala con crítica a las camaradas en general que, efectivamente, hacemos poca vida con las mujeres que no son del P[artido], que es con quienes en todo momento estamos obligadas a hacer un trabajo de masas $» .{ }^{72}$ Esta apelación a la unidad de las presas responde a las directrices de la dirección PCE en el exilio en relación con el activismo de las mujeres: en 1946 también se presentaba la Unión de Mujeres Españolas (UME) que, aunque tenía un claro predominio comunista, apelaba por la unidad de todas las mujeres antifranquistas. ${ }^{73}$

Otras acciones políticas de más baja intensidad desarrolladas por las presas de Ventas que han quedado reflejadas en los periódicos son las campañas denominadas «miércoles de resistencia». EI economato de la cárcel de Ventas tenía un recargo del $20 \%$ sobre el precio normal de la calle, ${ }^{74}$ por eso, esta acción iba destinada a evitar comprar en el economato ese día de la semana para impedir que los represores "vivan estupendamente a costa nuestra», intentando aumentar la llegada de paquetes de familiares y solidarizándose con las presas que no tuvieran familia que les llevara comida y productos básicos. ${ }^{75}$ Esto repercutía positivamente en el partido, pues algunas presas decidían donar lo ahorrado

\footnotetext{
${ }^{69}$ AHPCE, FPP, 13/20, Nuestro Guía, n.o 4, abril de 1946, pp. 2-3.

${ }^{70}$ Ibídem, p. 6.

${ }^{71}$ Ibídem, p. 1.

72 AHPCE, FPP, 13/20, Nuestro Guía, n.o 5, mayo de 1946, p. 3.

73 Mercedes YUSTA RodRigo, Madres coraje contra Franco. La Unión de Mujeres Españolas en Francia, del antifascismo a la Guerra Fría (1941-1950), Madrid, Cátedra, Feminismos, 2009, p. 117

${ }^{74}$ Carlos Fernández Rodríguez, Madrid clandestino. La restructuración del PCE, 1939-1945, Madrid, Fundación Domingo Malagón, 2002, p. 56.

${ }^{75}$ AHPCE, FPP, 13/20, Nuestro Guía, n. 2, febrero de 1946, p. 3.
} 
en un mes al PCE, en vez de al economato. ${ }^{76}$ La autofinanciación era otra de las actividades políticas más habituales de las presas comunistas de Ventas, como se recoge igualmente en las páginas de estas publicaciones, mediante la confección de paños, calcetines, muñecas, etc., esto permitía a las presas abastecerse y generar ingresos. ${ }^{77}$

\section{La vida cotidiana en la cárcel}

En la vida cotidiana de la prisión es donde mejor se aprecia cómo la cárcel fue una «ciudad clandestina». Ya hemos visto las recomendaciones por parte del PCE a sus militantes para que se relacionen con el resto de presas, pero no todas las presas eran iguales, pues no todas habían tenido las mismas vivencias ni presentaban el mismo perfil. En este sentido, las presas de las JSU criticaban el ambiente en el que se movían sus compañeras de prisión:

La juventud en la época anterior a la creación de la organización [las JSU] en esta, no vive como tal, sino como personas mayores olvidadas circunstancialmente por el peso del ambiente general excesivamente reflexivo, lleno de serias y fuertes preocupaciones [...]. Las muchachas de entonces no lo eran más que en edad. $^{78}$

No es de extrañar esta afirmación, pues la cárcel que conocieron las primeras presas políticas no fue la misma que la de los siguientes grupos de presas encarceladas en los primeros años de posguerra. El maltrato psicológico, la desposesión y su cosificación hacían que entraran jóvenes en prisión y salieran viejas. ${ }^{79}$ Eran dos realidades totalmente distintas que tenían que convivir en el espacio cerrado de la prisión y en la militancia del día a día. Por eso, las presas de las JSU reclaman su propio espacio de militancia, autónomo en lo político del PCE e independiente en lo organizativo, porque:

[...] las chicas que durante siete años han permanecido en la cárcel tienen un gran desconocimiento de la nueva juventud, y por lo tanto de las formas de trabajo con ella. La cárcel las ha hecho excesivamente serias, no comprenden (y no la sostienen) una conversación sobre bailes, piscinas, modas. Cuando España necesita todo nuestro esfuerzo y atención, pensar en eso es una «irresponsabilidad enorme», piensan ellas. No, no es irresponsabilidad, puesto que los jóvenes que dirijan al resto han de sostener las conversaciones que ellos inicien y han de saber iniciarlas sin establecer con su lenguaje y conceptos diferencias entre unos y otros que son muy perjudiciales en el trabajo. Es completamente negativo que con nuestra "superioridad» impidamos hablar y hacer a una muchacha, porque esto nos impide conocerla. ${ }^{80}$

Existen varias realidades en prisión, pero las presas que dirigían el PCE en Ventas tenían que coordinar a todas sus compañeras y continuar dichas realidades, ejerciendo un papel de dirección en un contexto difícil, por lo que tenían que estar dando constantemente directrices y denunciando los comportamientos que podían ser perjudiciales para todo el colectivo de presas comunistas. Así, por ejemplo, se criticaban las faltas de respeto a las funcionarias:

\footnotetext{
${ }^{76}$ AHPCE, FPP, 13/20, Nuestro Guía, n. 5, mayo de 1946, p. 2.

${ }^{77}$ AHPCE, FPP, 13/20, Nuestro Guía, n. 1, enero de 1946, p. 2.

${ }^{78}$ AHPCE, FPP, 12/11, Juventud Reclusa, n.o 11, 1 de junio de 1946, p. 1.

${ }^{79}$ Ricard VINYES, Irredentas..., op. cit., p. 129.

${ }^{80}$ AHPCE, FPP, 12/11, Juventud Reclusa, n.o 11, 1 de junio de 1946, p. 2.
} 
Bueno está protestar y no consentir que se cometan con nosotras arbitrariedades, pero eso siempre con causas justificadas y hecho con todo orden y responsabilidad, pues si no perderemos toda la razón [...]. No demos ocasión con nuestra conducta indisciplinada e irreverente a que nos sea aplicada la sanción que no puedan imponernos por las protestas justas y ordenadas que hagamos. ${ }^{81}$

También denunciaban, lógicamente, las situaciones inversas, como cuando se producía una arbitrariedad por parte de las funcionarias y las presas no respondían en bloque. ${ }^{82}$ Otros comportamientos por los que se pedían mesura y conciencia eran los que planteaban que no se gritara, o se abriera la puerta de improviso en las reuniones clandestinas; ${ }^{83}$ que los puntos de vista contrarios entre varias presas se debatieran en las reuniones internas y no "a los cuatro vientos»; ${ }^{84}$ o que en las reuniones donde se tomaban las decisiones sobre acciones concretas fueran partícipes, mientras que en el desarrollo de la acción no se fuera tanto. ${ }^{85}$ Pero uno de los aspectos que fue más duramente criticados por la dirección fue el de la compra de Redención por parte de dos militantes. Ya hemos analizado la importancia que tenía este periódico como mecanismo de adoctrinamiento por parte del régimen, y cómo el PCE, al igual que otras organizaciones, tenía una postura firme ya acordada en todos los órganos del partido de no comprarlo ni colaborar en sus páginas. Tras ser apercibidas, las presas «inculpadas» contestaron que lo hacían «a sabiendas de que el P[artido] no se lo podía consentir, por lo que esperaban su sanción». Tras esto, la dirección del PCE de Ventas trasladó a los órganos superiores del partido el caso para que allí se decidiera, y estos acordaran suspender su actividad política. ${ }^{86}$

Sin embargo, lo que más podía alterar la actividad política eran la monotonía y la pasividad de la prisión. Tras la actividad frenética de los primeros meses de 1946, el PCE no fue capaz de imponer un ritmo de activismo militante sostenido, sobre todo porque la situación interna del régimen de Franco, pese a la condena de la ONU, no cambiaba. Además, las medidas de excesiva seguridad del PCE para su militancia podían suponer una reducción del trabajo militante, aunque ello no debía ser excusa para que el PCE perdiera dinamismo, ${ }^{87}$ pues el principal fundamento del partido era la acción:

Nosotro[s] los comunistas nunca podemos permanecer inactivos, pues, en todo momento, tenemos multitud de tareas que realizar y es nuestra obligación pensar sobre el trabajo que podría llevarse a efecto en cada una de las circunstancias que atravesamos [...]. Aquí en Ventas no hay por parte de los militantes del P[artido] el dinamismo de combate que debiera existir. ${ }^{88}$

\footnotetext{
${ }^{81}$ AHPCE, FPP, 13/20, Nuestro Guía, n.o 2, febrero de 1946, p. 6.

${ }^{82}$ AHPCE, FPP, 13/20, Nuestro Guía, n.o 1, enero de 1946, p. 2.

${ }^{83}$ AHPCE, FPP, 13/20, Nuestro Guía, n.o 2, febrero de 1946, p. 6.

${ }^{84}$ AHPCE, FPP, 13/20, Nuestro Guía, n.o 5, mayo de 1946, p. 3.

${ }^{85}$ AHPCE, FPP, 13/20, Nuestro Guía, n.ㅇ 2, febrero de 1946, p.3.

${ }^{86}$ AHPCE, FPP, 13/20, Nuestro Guía, n. 4, abril de 1946, p. 3.

${ }^{87}$ Ibídem.

${ }^{88}$ AHPCE, FPP, 13/20, Nuestro Guía..., n.o 5, mayo de 1946, p. 1.
} 
Por esas razones se insiste a la militancia a que siga estrechando «relaciones, aunque sean de tipo personal, con todas las mujeres de la prisión», para seguir tejiendo redes y plantear futuros mecanismos de lucha en la cárcel en torno al PCE. ${ }^{89}$

\section{Autorrepresentación de las presas}

La percepción que tenían las presas de su propio partido y de sí mismas ha quedado registrada en sus publicaciones manuscritas. Aunque cada militante del PCE tenía unas características distintas en función de su espacio de militancia (carcelario, clandestino, en el exilio), todos compartían algunas características que tenían su tronco común en la idealización del partido.

Esta circunstancia de idealización del PCE se dio, sobre todo, por las circunstancias históricas en las que este partido desarrolló su actividad: la Guerra Civil, la II Guerra Mundial, y la dictadura franquista, en la que mantener a la organización era al mismo tiempo una batalla y un riesgo en el día a día. Esto facilitaba la mitificación en torno al partido, el acatamiento de su unidad y el repudio a la discrepancia. ${ }^{90}$ Es en este sentido que ser militante del PCE era un signo de prestigio y de gran responsabilidad frente al resto de la clase obrera y la sociedad. ${ }^{91}$ Esto se refleja a la perfección en las páginas de los periódicos analizados. Por ejemplo, en el n. 1 de Nuestro Guía, cuando se presenta la publicación en el editorial, se afirma que uno de los objetivos de la misma es que:

[...] ante nuestros camaradas presos, y los que en la calle luchan, dejemos bien sentado las comunistas de Ventas que nuestra mayor aspiración es el merecer por nuestros actos militar en el P[artido] C[omunista], y nuestro mayor ideal: el triunfo mundial del partido del proletariado. ${ }^{92}$

Otro claro ejemplo de esta concepción del partido y del "ser comunista» lo encontramos tras la huelga de hambre de enero 1946, y la experiencia que esta supuso para las presas:

Es seguro que al recordar aquellos días, aquellas horas tan condensadas de ansiedad, alteraciones y confianza de nuestra fuerza y razón, cada comunista siente que en su corazón se ensancha, que su deseo de lucha aumenta y que su orgullo de ser militante de nuestro querido P[artido] se hace mayor y mayor a cada instante. $^{93}$

En esa idealización de la vida política de la militancia comunista, se destaca que los comunistas tenían que ser un ejemplo y referencia para la sociedad, con su capacidad de sacrificio y su compromiso con la organización. Ya hemos visto algunas muestras de esta actitud en el caso de la visita de los niños a las prisiones el Día de Reyes y el boicot de las presas comunistas, algo que no fue seguido por quien

\footnotetext{
${ }^{89}$ Ibídem. 143. pp. 46-48.

92 AHPCE, FPP, 13/20, Nuestro Guía, n.o 1, enero de 1946, p. 1.

${ }^{93}$ AHPCE, FPP, 13/20, Nuestro Guía, n.o 2, febrero de 1946, p. 3.
}

${ }^{90}$ Francisco ERICE SEBARES, «El “orgullo de ser comunista”. Imagen, autopercepción, memoria e identidad colectiva de los comunistas españoles» en Manuel BuENo LLUCH y Sergio GálVEZ BIESCA (Eds.), Nosotros los comunistas. Memoria, identidad e historia social, Madrid, Fundación de Investigaciones Marxistas / Atrapasueños, 2009, p.

91 David GINARD I FERRON, «Sobre héroes, mártires, tumbas y herejes. Culturas militantes de los comunistas españoles (1939-1962)», en Manuel BUENo LLUCH y Sergio GÁlVEz BiesCA (Eds.), Nosotros los comunistas..., op. cit., 
no tenía una conciencia tan depurada, o en el caso del periódico Redención y las militantes que lo adquirieron para beneficiarse de los privilegios que implicaba su compra. En Juventud Reclusa encontramos el testimonio de una militante de las JSU muy interesante en este sentido:

En los siete años que llevo en la cárcel he pasado por unas etapas algo [cंinsidiosas?], y por mí juzgo lo que la JSU significa y lo que puede ayudar a una joven cuando no se tiene energía [...]. Una de estas muchachas he sido yo. He tenido una época en la que reconozco hoy, no supe comportarme como una joven revolucionaria con una preparación ya, puesto que antes de venir a la cárcel era de la JSU: frivolidad, falta de energía, cobardía ante la posibilidad de que me fusilaran, han sido los motivos de mi mal comportamiento durante esta época en que, olvidándome de lo que era, claudiqué y me dejé arrastrar por donde mis enemigos quisieron llevarme.

Esto representa mi mayor vergüenza y no quiero pensar que nadie pueda pasar una situación parecida [...]. Me faltó el apoyo de la Juventud, me faltaba su orientación. ${ }^{94}$

Ya se ha señalado cómo el centralismo democrático y la unidad de acción del PCE favorecían el desarrollo de la actividad clandestina. En las páginas de Nuestro Guía, sobre todo, se difundían artículos que ayudaran a comprender a la militancia este modelo de funcionamiento orgánico del partido, destacando que "La voz comunista después de un profundo estudio de los problemas, ha de llegar unánime al pueblo», ${ }^{95}$ y que esta disciplina no es "el "ordeno y mando" de cuartel, ni es tiránica por la imposición de arriba abajo. La disciplina comunista es la consecuencia de un amplio y profundo estudio y razonamiento del porqué y para qué de las cosas». ${ }^{96}$

Otra cuestión que se aprecia en los periódicos manuscritos son las múltiples referencias a los líderes del partido. Son constantes las citas célebres de Dolores Ibárruri o de José Díaz. De hecho, se quiso mantener fija una columna denominada "Conozcamos a nuestros dirigentes», aunque no siempre se pudo por falta de artículos. Cuando se analizan los testimonios escritos hay que ver lo que se escribe y plasma en el papel, pero también la información que se omite. En el caso de la biografía que dedica este periódico a José Díaz llama la atención la ausencia de referencias a su suicidio. Concretamente se dice lo siguiente:

No abandonó la lucha, a pesar de padecer una gran enfermedad, hasta que agotado en [¿̇grado?] máximo tuvo que marchar a Moscú, donde se le practicó una delicada operación, siendo imposible salvar la vida de este gran luchador. ${ }^{97}$

Obviamente, no se dice ninguna mentira, sino que se omiten hechos: no se pudo salvar su vida, pero omiten que se suicidó al no poder soportar por más tiempo los dolores derivados de su enfermedad. La imagen que se pretende difundir de los líderes como reflejo de la moral de un ideal para dar fuerza a la militancia presa de sufrimientos a veces choca con la conducta en la vida personal de los líderes. ${ }^{98}$ Aunque también hay que tener en cuenta que desconocemos la procedencia de la fuente, si la dirección local de Ventas conocía o no todos los datos, o si se limitaron a transcribir la

\footnotetext{
${ }^{94}$ AHPCE, FPP, 12/11, Juventud Reclusa, n. 11,1 de junio de 1946, p. 5.

${ }^{95}$ AHPCE, FPP, 13/20, Nuestro Guía, n. 1, enero de 1946, p. 1.

${ }^{96}$ AHPCE, FPP, 13/20, Nuestro Guía, n. 2, febrero de 1946, p. 1

${ }^{97}$ AHPCE, FPP, 13/20, Nuestro Guía, n.o 1, enero de 1946, p. 3.

${ }^{98}$ Francisco ERICE SeBARES, «El “orgullo de ser comunista”...», op. cit., p. 154.
} 
información que recibían. Pero eso es otra cuestión que es importante a la hora de tener en cuenta hasta donde llega la mitificación de los líderes.

\section{Los roles de género}

Las presas comunistas en Ventas no vivieron ajenas a la sociedad patriarcal dominante. Fruto de su educación reprodujeron buena parte de los roles de género imperantes en la época, entre los cuales había que destacar el discurso de la domesticidad, el reparto de labores y el papel de las mujeres con respecto a la familia y al marido o compañero varón, así como los intentos de resistencia al modelo patriarcal tradicional. Todo ello se puede apreciar también en las páginas de los periódicos manuscritos.

Desde el primer momento nos encontramos un discurso que apela a la maternidad de las presas para alcanzar determinados objetivos políticos: «Lo mismo que las madres cuidan a sus hijos con gran cariño, así nosotras tenemos que velar y cuidar con todo esmero la unidad de nuestro P[artido]». ${ }^{99}$ Entre las mujeres que militan en el PCE son constantes las referencias a la maternidad, ya que por su parte hay una estrategia de apropiación de los símbolos ligados a la maternidad para conseguir una autoridad, legitimar sus intervenciones y reafirmar la justicia de sus demandas. ${ }^{100}$ Esto forma parte de un modelo de feminidad/maternidad, cuyo máximo exponente es Dolores Ibárruri, que no implica la pasividad, sino que se caracteriza por la entrega de la mujer a sus hijos, maridos y al socialismo, pero nunca a sus propias reivindicaciones. ${ }^{101}$

Hay un artículo muy interesante en el n.o 4 de Nuestro Guía dedicado íntegramente a la emancipación de la mujer que merece un análisis pormenorizado. El artículo comienza mencionando los avances de las mujeres en el acceso a derechos básicos, sobre todo en el periodo de la II República y de la Guerra Civil, en el plano cultural, social y político, alcanzando espacios y esferas que «en otra época solo han estado abiertas a los del sexo contrario por considerar a la mujer en un plano de inferioridad». Esto, sin embargo, no era suficiente para la emancipación, pues resultaba necesario "que cada día desterremos de nosotras la educación llena de falsos prejuicios que la sociedad capitalista ha procurado inculcarnos». ${ }^{102}$ De ahí la crítica al modelo tradicional de feminidad basado en la maternidad:

Hoy día aún oímos de los labios de camaradas comunistas que su aspiración es constituir un hogar y educar a sus hijos, considerando esto aportación suficiente por su parte a la sociedad. Pues bien, si pensamos tener derecho a una igualdad de condiciones dentro de la sociedad y del Estado, tenemos que conquistarla. ¿Por qué han de ser únicamente los hombres los que contribuyan económicamente al mantenimiento del hogar? ${ }^{103}$

\footnotetext{
99 AHPCE, FPP, 13/20, Nuestro Guía, n.o 1, enero de 1946, p. 1.

${ }^{100}$ En lo referente al discurso de la maternidad entre las mujeres militantes del PCE hay que destacar el estudio que hace al respecto Mercedes Yusta analizándolo a través del periódico de la UME: Mujeres Antifascistas Españolas. Visto en: Mercedes YUSTA RodRIGO, Madres coraje contra Franco..., op. cit., pp. 240-278.

${ }^{101}$ Claudia CABRERo BLANCO, «EI PCE y las mujeres. La actitud del PCE respecto a la militancia femenina durante el primer franquismo», en Manuel Bueno LluCH; José HinojosA; Carmen García García (Coords.), Historia del PCE..., op. cit., p. 438.

${ }^{102}$ AHPCE, FPP, 13/20, Nuestro Guía, n. 4, abril de 1946, p. 7.

103 Ibídem.
}

HISPANIA NOVA., 15 (2017), págs. 147-171 DOI: https://doi.org/10.20318/hn.2017.3484 
Aunque marcan distancias con respecto al reparto tradicional de las esferas pública y privada, todo se orienta a un fin, el mantenimiento del hogar. De hecho, matizan sus palabras para entender que no atacan a la familia: «Entiéndase bien que no significa esto que las mujeres comunistas seamos opuestas a la formación del hogar y la familia, pues por el contrario propugnamos abiertamente por ello como base cálida para sustentar una sociedad perfecta». ${ }^{104}$

Aunque una de las acusaciones que siempre se ha realizado a las organizaciones comunistas es la de disolver los vínculos familiares tradicionales, por el contrario, las mujeres del PCE, y el propio partido, se caracterizan por reforzar el modelo de familia tradicional. ${ }^{105}$ Esto ha de relacionarse con el hecho de que la mayoría de las mujeres que ingresaban en el PCE lo hacen a causa de las relaciones que tenían con otros hombres. Las motivaciones afectivas constituyeron el impulso decisivo y casi incuestionable que las llevaron a adquirir su compromiso político. ${ }^{106}$ De hecho, como ya hemos visto en la falta de respuesta al boicot de las visitas de los hijos de las presas, el franquismo utilizaba esta realidad para chantajear y enfrentar a las presas entre sí y obligarlas a priorizar entre su papel de madre o de militante.

Continúa el artículo planteando la necesidad de una educación mejor para reunir las condiciones necesarias para lograr la independencia económica y conseguir de ese modo "que los hombres coloquen a la mujer en el plano que se merece, y en las mujeres desterrar el concepto de que somos esclavas solo aptas para tener hijos, en lugar de la compañera que debe comprender al hombre y alentarle en todas luchas y aspectos de la vida». ${ }^{107}$ Aunque rechazan el papel exclusivo de la mujer dedicado a la maternidad, no rompen con la barrera tradicional de papel secundario relegado: tiene que ser el hombre quien coloque a las mujeres en el ámbito político y en otros ámbitos de la vida, no ellas mismas. Además, tiene que "comprender» y «alentarle» en todas las luchas, lo que perpetúa esa labor asistencial y de estímulo masculino que la mujer había ya jugado en la Guerra Civil. Así, la esfera pública seguiría en manos del varón.

El reparto de tareas en la prisión también evidencia la diferencia de roles de género y su naturalización, ya que la mujer realizaba tareas "más propias de su sexo», como la elaboración de paños, calcetines, toquillas, muñecas, pañuelos, etc. ${ }^{108}$ Este trabajo no contaba como «redención de penas», respondiendo a la tradicional invisibilización del trabajo doméstico, pero era permitido por la dirección de la prisión porque era una forma de combatir el ocio, considerado como una "fuente pecaminosa». Los ingresos de este trabajo iban normalmente a parar a la familia, ${ }^{109}$ pero en el caso de las presas comunistas estaban destinados al PCE, como así quedaba reflejado en las páginas de Nuestro Guía:

\footnotetext{
${ }^{104}$ Ibídem.

105 Xavier DOMÈNECH SAMPERE, «Cenizas que ardían todavía: la identidad comunista en el tardofranquismo y la transición», en: Manuel Bueno LluCH y Sergio Gálvez BIESCA (Eds.), Nosotros los comunistas..., op. cit., p. 127.

${ }^{106}$ Claudia CABRERo BLANCO, «El PCE y las mujeres....», p. 432.

${ }^{107}$ AHPCE, FPP, 13/20, Nuestro Guía, n. 4, abril de 1946, p. 7.

${ }^{108}$ AHPCE, FPP, 13/20, Nuestro Guía, no. 1, enero de 1946, p. 2.

${ }^{109}$ Fernando HeRnÁNDEZ Holgado, Mujeres encarceladas..., op. cit., pp. 292-295.
} 
La C[élula] n.o 4 es la que más se ha destacado en esta galería [la 2. a derecha] por su entusiasmo y dinamismo en el trabajo. Las camaradas de esta C[élula] han hecho 56 pañuelos que proporcionarán al P[artido] 133 pts. ¿Verdad qué os sentís satisfechas de proporcionar al P[artido] tan magnífico ejemplo?

Estimulamos a una camarada de esta misma C[élula] que ella sola ha hecho un paño grande que se ha rifado en la calle, cuyo importe íntegro pasará al P[artido]. iMuy bien, camarada! ${ }^{110}$.

\section{El papel de la formación}

En general, nosotras decíamos que éramos comunistas, más que nada por instinto revolucionario [...]. Si alguien nos hubiera preguntado por qué éramos comunistas no nos hubieran [¿faltado?] argumentos, pero estos no hubieran sido todo lo sólidos y convincentes que lo son hoy. Hay un abismo entre aquellas mujeres que entraron en la cárcel hace siete años y nosotras. ${ }^{111}$

Esta frase resume a la perfección el papel que tuvo la formación política en prisión. Hay que tener en cuenta que la mayoría procedía de una extracción social baja, generalmente de origen rural, donde más dificultad había encontrado la labor pedagógica de la República y de las organizaciones de mujeres en la Guerra Civil; por eso su nivel de instrucción era, por norma general, bajo o nulo. ${ }^{112}$ A esto hay que sumar que la mayoría de presas apenas había tenido contacto con la política hasta la propia Guerra Civil, siendo su labor colaborar con el partido en tareas complementarias y asistenciales. Por eso, partían de una situación de desigualdad con respecto a sus compañeros varones, y ahí es donde la cárcel adquiere protagonismo como espacio de formación para las presas, reforzando un aspecto en el que apenas habían tenido oportunidad de profundizar al tener que dedicarse en libertad a otras tareas domésticas, familiares y también políticas:

Siendo para nosotras una de las principales tareas el capacitarnos culturalmente, debemos aprovechar este precioso tiempo que nos brindan las circunstancias actuales, ya que una vez entregadas a la vida normal nuestro problema económico y nuestras actividades políticas lo absorberán, no permitiéndonos adquirir estos conocimientos tan necesarios en la vida.

[...] cuando se tiene la voluntad de aprender se aprende sabiendo que con esta arma combatimos también al enemigo que puso y pondrá siempre todo su empeño en mantener al pueblo en la ignorancia. Aquí, entre nosotras, vemos magníficos ejemplos de voluntad y entusiasmo por parte de muchas mujeres ya mayores que habian sido completamente analfabetas y que hoy sostienen su correspondencia particular, y de muchachas que han sabido aprovechar estos años de reclusión y saldrán facultadas para desenvolverse en mejores condiciones. ${ }^{113}$

La cárcel supuso una continuación de la lucha contra el analfabetismo que se produjo en la República y en los años de la Guerra Civil. El procedimiento a seguir era que las presas que tenían más conocimientos y formación instruían a las presas en cultura elemental:

\footnotetext{
${ }^{110}$ AHPCE, FPP, 13/20, Nuestro Guía, n. 1, enero de 1946, p. 2.

${ }^{111}$ AHPCE, FPP, 13/20, Nuestro Guía, n. 5, mayo de 1946, p. 5.

112 Ángeles EGIDO LEÓN, El perdón de Franco. La represión de las mujeres en el Madrid de Posguerra, Madrid, Catarata, 2009, pp. 97-98

${ }^{113}$ AHPCE, FPP, 13/20, Nuestro Guía, n. 2, febrero de 1946, p. 3.
} 
Con entusiasmo las profesoras nos dan gran parte del tiempo que por las mañanas necesitan para su aseo personal y arreglo de la celda, poniendo todo su empeño en enseñarnos todos los conocimientos que ellas, más afortunadas, poseen. ${ }^{114}$

Como se puede ver en las páginas de Nuestro Guía, una de las actividades formativas que se desarrollaban en Ventas eran los "cursillos de capacitación» con contenidos «elementales» para la militancia del PCE en Ventas. El objetivo era la capacitación política de las presas, preservando la identidad comunista y su naturaleza política, pero con una visión a medio o largo plazo: «cuando estas compañeras se incorporen a la lucha en la calle lo harán con mayor conocimiento y con más elementos para resolver cuanto en el terreno político se les presente ${ }^{115}$ La formación fue así un elemento para poder seguir desarrollando la actividad política en el exterior una vez obtenida la liberad, lejos de haber sido redimidas y convertidas por los elementos coercitivos del franquismo. Así lo exteriorizaban en las páginas de Nuestro Guía: «Mujer comunista, dime: Si salieras en libertad, ¿qué harías políticamente?» ${ }^{116}$

En Juventud Reclusa se recoge el testimonio de una presa que se marcha de la cárcel y escribe en el periódico para despedirse de sus compañeras, plasmando personalmente su objetivo tras la salida de prisión: «yo prometo, camaradas, que, a pesar de que no estoy lo suficiente preparada, no [voy a] desviarme de seguir luchando hasta poder lograr lo que tanto ansiamos los que nos hayamos bajo el yugo criminal fascista». ${ }^{117}$

\section{CONCLUSIONES}

Paradójicamente, a pesar de las condiciones de las presas y de las hostilidades de la represión diferenciada, la censura, la persecución política y el peso de los roles de género, la cárcel supuso para ellas una oportunidad única para formarse y ejercer un cierto empoderamiento que hubiera sido imposible en el exterior de prisión.

Al estar estas presas políticas en cárceles exclusivamente de mujeres, ya no podía producirse que sus organizaciones las colocaran en tareas secundarias, infravalorando sus capacidades políticas. Ahora ellas eran las que ocupaban los órganos de dirección y aplicaban las directrices y la acción de sus organizaciones en su ámbito de actuación: la cárcel de Ventas. De esta forma, el proceso de subversión de los roles de género, de intervención en la esfera pública y de formación y capacitación de las mujeres que se inició en la II República continúa en prisión, a pesar de los intentos por parte del franquismo por evitarlo. En esta tarea los periódicos manuscritos jugaron un papel fundamental. El propio hecho de participar y elaborar contenidos para las publicaciones ya era un acto formativo $y$, al mismo tiempo, una doble subversión: política y de género. Una subversión de género porque este tipo de escritura no era íntima, sino que implicaba tomar la palabra, cuestionarse la realidad y buscar alternativas, por eso, esto choca con el perfil de mujer sumisa y pasiva que quería imponer el franquismo. También era una

\footnotetext{
114 Ibídem.

${ }^{115}$ AHPCE, FPP, 13/20, Nuestro Guía, n. 1, enero de 1946, p. 6.

${ }^{116}$ Ibídem, p. 5.

${ }^{117}$ AHPCE, FPP, 12/11, Juventud Reclusa, n. 11, p. 3.
} 
subversión en el contexto político y carcelario, porque suponía un mecanismo de resistencia frente al control y sometimiento del franquismo.

Estos periódicos hicieron más fácil el día a día en la prisión, al tiempo que posibilitaron a las mujeres el sentirse incluidas en una organización de la importancia de «El P[artido]», compuesto por históricos luchadores y luchadoras que, según su autorrepresentación, siempre habían estado a la altura de las circunstancias. A veces se puede caer en la divinización de estos, o en su deshumanización (como el caso citado de Pepe Díaz), pero no dejan de ser recursos que se utilizan para dar fuerzas y energías a las presas y así animarlas a seguir luchando. Son elementos sin los cuales, seguramente, buena parte de la militancia presidiaria se hubiera dejado llevar por la ola de redención, para poder salir antes de prisión y reingresar en la sociedad. Son aspectos, por tanto, que solo en ese contexto de extrema necesidad se pueden entender.

Tampoco se pueden entender estos periódicos sin su utilidad para poder plantear una respuesta política a un régimen que se había impuesto por la fuerza de las armas, con los medios que se tuvieran a mano: la creación de un espacio de activismo con objetivos de denuncia de las atrocidades del franquismo, de reorganización militante y de capacitación formativa de dirigentes políticos.

Finalmente, se puede señalar que estos periódicos son un elemento indispensable para entender y comprender el activismo político en un ambiente tan represivo como el de las cárceles del franquismo. El estudio de los productos escritos desde una perspectiva social es, junto a las fuentes orales, una de las pocas vías o mecanismos que permiten hoy reconstruir y reivindicar la memoria política de las presas de Franco, algo indispensable para la historia, que tiene que posicionarse ante aquellos planteamientos que tratan de negar e invisibilizar los conflictos que se producen en la sociedad, como son los de clase o género. 